Data de recebimento do artigo: 22-10-2017

Data de aceite do artigo: $15-04-2018$

DOI: https://doi.org/10.7769/gesec.v9i2.686

\title{
Comunicação intercultural e os desafios do profissional em Secretariado
}

\section{Executivo em organizações multinacionais}

\author{
Ana Cristina Batista de Paula \\ Bacharela em Secretariado Executivo Trilíngue pela Universidade Federal de Viçosa (UFV). \\ E-mail: anacrist.batista@gmail.com (Brasil)

\section{Glauber Heitor Sampaio} \\ Doutorando em Linguística Aplicada na Universidade Estadual de Campinas (Unicamp). \\ Mestre em Letras pela Universidade Federal de Viçosa (UFV). \\ E-mail: glauberhsampaio@gmail.com (Brasil)
}

\section{RESUMO}

O fenômeno da interculturalidade manifesta-se cada vez mais nas organizações multinacionais como resultado do estreitamento das fronteiras empresariais através de um contínuo processo de globalização que permite o acesso de diferentes países ao cenário corporativo nacional e vice-versa. Nesse cenário, diversos profissionais têm contato cotidiano com diferentes línguas e culturas e novos desafios são postos aos que transitam nesses contextos. Por esse motivo, o objetivo desta pesquisa é investigar quais são os desafios que os profissionais egressos do curso de Secretariado Executivo Trilíngue de uma Universidade Federal mineira encontraram nas organizações multinacionais em relação à comunicação intercultural em sua prática profissional diária. Para tanto, buscou-se analisar como a formação acadêmica colaborou para que um grupo de profissionais lidassem com encontros interculturais em seus respectivos locais de atuação. Trata-se de um estudo qualitativo, de cunho descritivo, que se utiliza de narrativas escritas sobre experiências de formação e atuação profissional em organizações multinacionais. Como resultado, os participantes mostraram que o conhecimento a respeito de ambientes multiculturais necessita ser mais bem compreendido, debatido e explorado para que os profissionais se tornem de fato mais capacitados para lidar com os trâmites próprios da carreira em organizações multinacionais.

Palavras-Chave: Interculturalidade. Formação profissional. Secretariado Executivo. 


\title{
Intercultural communication and the challenges of the Executive Secretariat at multinational organizations
}

\begin{abstract}
The intercultural phenomenon is increasingly apparent in multinational organizations as a result of close business frontier ties through the ongoing process of globalization, which allows different countries accessing the national corporate scheme and vice versa. In this scenario, a great deal of professionals begins having daily contact with different languages and cultures and new challenges are posed to those who navigate this professional milieu. The goal of this research is to investigate the challenges which professionals, holding a degree in Trilingual Executive Secretariat from a Federal University in the State of Minas Gerais, may face in a daily basis within multinational organizations. Therefore, we sought to analyze how well the degree program prepared these professionals to deal with intercultural encounters in their respective workplaces. This is a qualitative research which uses narratives, guides, and questionnaires for data gathering. As a result, the experience of the participants shows that the structure of multicultural environments needs to be better understood, debated, and explored through the courses offered to students majoring in Secretariat, so that they may become more capable leaders and exhibit the competence required of a career within multi-national companies.
\end{abstract}

Keywords: Interculturality. Vocational training. Executive Secretariat.

\section{Como referenciar em APA:}

De Paula, A. C. B. \& Heitor-Sampaio, G. (2018). Comunicação intercultural e os desafios do profissional em secretariado executivo em organizações multinacionais. R.G.Secr.,GESEC, 9(2). DOI:

\section{Como referenciar em ABNT:}

PAULA, A. C. B.; HEITOR-SAMPAIO, G. Comunicação intercultural e os desafios do profissional em secretariado executivo em organizações multinacionais. R.G.Secr.,GESEC, v. 9, n. 2, 2018. DOI:

\section{THOMSON REUTERS}
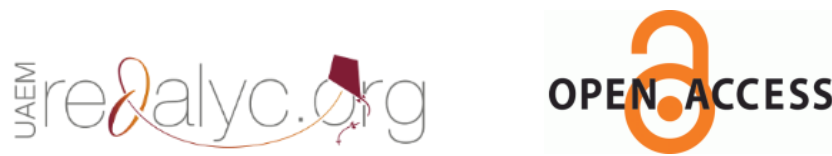

R.G. Secr., GESEC, São Paulo, v. 9, n. 2, p 72-95, mai./ago. 2018. 


\section{Introdução}

A interculturalidade é um fenômeno que advém essencialmente do contato entre sujeitos que não compartilham dos mesmos referentes simbólicos e, por essa razão, a comunicação tende a sofrer pela ocorrência de eventuais conflitos. Tal fenômeno não é próprio da contemporaneidade. Contudo, desenvolveu-se, principalmente, à medida que a expansão da globalização atenuou fronteiras, facilitou o acesso a outros países por meio do intercâmbio de organizações diversas para além do contexto nacional, e fez com que se instalassem em diferentes países como forma de crescimento econômico global. Como observa Freitas (2008), a convivência intercultural assume uma posição de destaque na vida social e no cenário organizacional, transformando-se em uma vantagem para aqueles que desejam compreender com mais profundidade o mundo dos negócios. Ao compreender o outro e as suas potencialidades, tornamo-nos mais aptos para nos apropriar da diversidade do mundo e dos mercados, fazendo com que os processos, estruturas e tomadas de decisões sejam mais eficientes.

Nesse cenário, portanto, profissionais em geral passaram a ter contato cotidiano com uma grande clientela advinda de múltiplos antecedentes culturais e linguísticos que inevitavelmente necessitam de um cuidado especial para que se efetivem trâmites sem maiores prejuízos aos envolvidos. Dentro de tal contexto, encontra-se o profissional de Secretariado Executivo, que é responsável pelo assessoramento das diretorias e dos setores estratégicos da empresa e que, ademais, exerce o papel de comunicador entre as áreas mencionadas. Por esse motivo, além de habilidades especificamente administrativas, exige-se também de tal profissional, proficiência em diferentes línguas, uma vez que as organizações buscam por profissionais que possam contribuir para a estabilidade da comunicação frente às mudanças proporcionadas pelo fenômeno da globalização.

Segundo Craide e Silva (2012), a interculturalidade nos aspectos organizacionais faz com que o ambiente de trabalho exija o desenvolvimento de novas aptidões e habilidades para que saibamos lidar com a realidade de encontros e convívio entre diferentes culturas, no sentido de melhor compreendê-las e aceitá-las. Por causa dessa necessidade, demanda-se do profissional em Secretariado Executivo uma atuação que seja capaz de agenciar relações interculturais no contexto de trabalho, pois além de ser responsável por assessorar setores de uma empresa, é também o elo comunicativo entre eles. Sobre essa questão, Sabino e Rocha (2004) salientam que há um papel didático do secretário executivo que é facilitado pela vasta pluralidade de relações que este estabelece com os vários setores e níveis hierárquicos 
empresariais. Ao assumir a posição de "elo" entre a alta administração e as outras repartições da empresa, o secretário executivo também deve se responsabilizar a promover o despertar da consciência de valores éticos junto aos seus pares. Conforme tais pesquisadores, "esse despertar pode ser iniciado pelo incentivo à compreensão dos valores individuais em relação ao bem comum (Sabino \& Rocha, 2004, p. 38).

A Comunicação Intercultural (doravante CI) traz novos desafios e exige dos profissionais que se inserem em organizações multinacionais habilidades particulares para proporcionar fluidez a um ambiente de trabalho multicultural, em que o saber interagir entre culturas é um fator imprescindível para que a equipe, como um todo, possa manter relações não conflitantes no que diz respeito aos interesses comuns dos envolvidos nos procedimentos institucionais.

Dentro dessa perspectiva, este estudo objetivou investigar os desafios profissionais de secretários executivos que trabalham em organizações multinacionais e que possuem contato diário multicultural. Além disso, de forma secundária, observar a necessidade de educação formal em nível superior mais especializada no que concerne o conhecimento de interações interculturais e seus desdobramentos em suas atuações cotidianas.

A escolha do tema justificou-se pela observação de certa carência de abordagem a fatores próprios dos estudos culturais referentes à interculturalidade e comunicação intercultural no programa das disciplinas da graduação em Secretariado Executivo de uma universidade mineira. $\mathrm{Na}$ grade curricular do referido curso são oferecidos níveis básico e intermediário dos idiomas Inglês, Francês e Espanhol cujo objetivo é instrumentalizar os futuros profissionais a se comunicarem e bem expressarem nessas línguas estrangeiras. Há também na grade curricular do curso os níveis de língua com foco "empresarial”, nos quais são lecionados os trâmites organizacionais nesses três idiomas. São exemplos de alguns dos conteúdos abordados no curso a "construção de currículos", "criação de planos de negócios" e "elaboração e apresentação de reuniões". As disciplinas organizam-se de forma a privilegiar vieses mais técnicos e práticos que serão posteriormente utilizados pelos alunos, futuros profissionais de Secretariado Executivo, e que os auxiliarão nos serviços requeridos pelas empresas.

Tais fatores mostraram-se relevantes para a realização de estudos acerca do conhecimento em interação intercultural que devem lançar mão para, dessa forma, poderem lidar com os mais diversos desafios que são postos em ambientes multiculturais. 
Para alcançar os objetivos propostos por esta pesquisa, foi realizado um levantamento de episódios em que tais profissionais presenciaram problemas de comunicação conflitantes no dia a dia corporativo, em encontros ditos interculturais, para poder discutir como o conhecimento sobre cultura e interculturalidade os ajudaram a compreendê-los e a resolvê-los de forma hábil ou não.

\section{A Comunicação Intercultural}

\section{A interação na comunicação intercultural}

Devido ao constante deslocamento de fronteiras de comércio nacionais, por meio da união entre países, acordos econômicos, aberturas de corporações em diferentes regiões e o fácil acesso ao mercado internacional proporcionados pela globalização, tornou possível que o contato com idiomas, costumes e culturas crescesse e se tornasse lugar comum nas relações profissionais.

Nesse contexto, encontra-se o conceito de interculturalidade, que se apresenta como "o conjunto dos processos psíquicos, relacionais, grupais, institucionais [...] originados pelas interacções [sic] das culturas, numa relação de trocas recíprocas e numa perspectiva de salvaguarda de uma relativa identidade cultural dos parceiros em relação". (Clanet, 1993, p. 21). Ainda sobre tal conceito, Ramos (2009, p.19) ressalta que o "intercultural implica relação, diálogo e comunicação entre as diferentes culturas, através dos indivíduos e grupos portadores dessas culturas, [...] em situações, na qual se encontram e interagem indivíduos, grupos e instituições originários de universos culturais diferentes” (Ramos, 2009, p.19).

Tendo em vista a interação dos diferentes grupos culturais, é necessário desenvolver a habilidade de saber comunicar-se em uma multiplicidade de contextos e situações:

O paradigma intercultural vem introduzir a diversidade, a pluralidade, a heterogeneidade, a complexidade, a interdisciplinaridade na pesquisa e na intervenção; permite apreender as situações e os problemas em termos de dinâmicas, de processos, de relações e de estratégias; implica uma atitude de descentralização e uma ética da relação humana e da relação pedagógica; implica o desenvolvimento de competências individuais, interculturais e de cidadania. (Ramos, 2009, p. 238).

É a diversidade cultural que distingue a comunicação intercultural dos outros tipos de comunicação. Com ela são trazidas as crenças, os valores, as normas e as regras de comportamento de cada cultura. É por esta heterogeneidade que se faz necessário ter atenção à identidade cultural de cada lugar, para assim, deixarem-se de focar nas diferenças para, 
então, focalizar na capacidade de interação mútua que o diálogo intercultural proporciona. Segundo Ferrari (2015), a promoção do diálogo intercultural conflui "em grande medida com a abordagem de identidades múltiplas" (Ferrari, 2015, p. 59). Não se deveria percebê-lo como perda da subjetividade cultural do interlocutor, mas como algo que depende do conhecimento que ele tem de si mesmo, do outro e de sua capacidade de passar um conjunto de suas próprias referências ao outro de maneira a apreciar o que ele tem a dizer, a respeitar a forma como diz e a entender os porquês de se comportar da forma como comporta.

A diversidade cultural e a interculturalidade faz cada vez mais parte dos aspectos econômicos, políticos, sócio-históricos e educativos de cada sociedade. A diversidade cultural é, segundo a Organização das Nações Unidas para a Educação, a Ciência e Cultura, na Declaração Universal sobre a Diversidade Cultural, artigo 3, "uma das fontes de desenvolvimento, entendido não só como crescimento econômico, mas também como meio de acesso a uma existência intelectual, afetiva, moral e espiritual satisfatória" (Unesco, 2001, p. 23).

Assim, a comunicação e o diálogo intercultural são aspectos cada vez mais presentes nas conjunturas sociológicas e ideológicas, e a abordagem intercultural requer que conheçamos minimamente essas conjunturas e perspectivas, tendo em vista que a eficácia da comunicação se baseia, sobremaneira, no que se sabe sobre as circunstâncias e hábitos de cada comunidade. Nesse sentido é que a seguir, apresenta-se o lugar da interculturalidade nas organizações multinacionais.

\section{A interculturalidade nas organizações multinacionais}

A expansão de empresas multinacionais tem como precursora a busca pelo fortalecimento de economias internacionais por meio da colaboração de novos contatos e mercados. A conquista de territórios em diferentes culturas fez com que as organizações tivessem proximidades com novas formas de operar e negociar. Com isso, é notável a necessidade de saber sobre a cultura, política, legislação e economia do país no qual as instituições pretendem se expandir. Entender sobre esses quesitos influencia nas decisões de negociações e no sucesso que a organização alcança fora do seu território. Segundo Martinelli, Ventura e Machado (2004), a cultura consiste em vários componentes sendo que dentre eles estão o "conhecimento, as crenças, valores, hábitos, costumes, opiniões e tradições de uma população que, quando considerados em sua totalidade, constituem-se num conjunto

R.G. Secr., GESEC, São Paulo, v. 9, n. 2, p 72-95, mai./ago. 2018. 
organizado para a interpretação da realidade” (Martinelli, Ventura e Machado, 2004, p. 21). Como evidenciam os mesmos estudiosos, o conhecimento e entendimento de hábitos, costumes e tradições de um dado povo é imperativo para que se instaurem relações profundas, solidas e duráveis (Idem, 2004)

Nas organizações multinacionais, a interação intercultural se faz presente em diversas circunstâncias, seja na abertura de uma sede em outro país, seja na adaptação do seu produto ou serviço para determinado mercado; seja por meio do contato com diferentes fornecedores ou nas reuniões de negócios nas quais a presença de representantes de outras nações é requerida. Por ocasião desse contato com diferentes sujeitos, advindos de experiências culturais distintas, as empresas, que não operam sozinhas e no "vácuo",

leem as macrotendências do meio e absorvem, com relativa rapidez, as grandes mudanças que nele ocorrem ou poderão ocorrer, dando respostas apropriadas aos seus objetivos de crescimento e expansão. Em outras palavras, hoje, as empresas se confrontam com o problema dos encontros de culturas como jamais antes no seio de suas atividades (encontro que já existia no social mais amplo), impondo-se como uma questão a ser gerida no nível organizacional. (Freitas, 2008, p. 80).

Tendo em vista este cenário, o reconhecimento do valor de cada cultura, das formas de agir, de se portar e de abordá-las, tornou-se um fator intrínseco haja vista que proporciona uma relação mais contígua que carece de ser mais propriamente mediada. Nesses termos, Damen salienta que

\footnotetext{
a interação de padrões culturais variados, crenças e valores que cada interlocutor traz ao processo de comunicação intercultural deve ser reconhecido em todo ato comunicativo; quanto maior a variação destes padrões, mais forte torna-se a força divisiva de tais variantes e maiores são as chances de falhas na comunicação (Damen, 1987, p. 24)
}

Como é perceptível, a necessidade de se pensar interculturalmente nesses microcontextos profissionais parece, cada vez mais acentuadamente, fazer parte das novas filosofias corporativas para que se mantenham ou se desenvolvam relações cada vez mais fluidas para uma melhor política empresarial na ordem de que se estabeleçam laços e parcerias cada vez mais saudáveis e duradouras. São em tais situações que o profissional em Secretariado Executivo, portando bagagem intercultural compatível para lidar e resolver problemas tende a se destacar e se fazer cada vez mais essencial no meio corporativo.

\section{O perfil do profissional em Secretariado Executivo e a comunicação intercultural}

Sabe-se que a profissão de Secretário Executivo era exercida por homens que eram denominados "escribas" na dinastia macedônica e aqueles são, portanto, considerados os precursores da profissão, pois exerciam função de secretários dos governantes, faziam 
registros das guerras, tinham acesso as literaturas e eram homens cultos e dotados de excelente habilidade para a escrita (Nonato Júnior, 2009). Por terem exercido funções como essas - de redatores a conhecedores de outros idiomas -, os escribas foram traçando algumas das atribuições do profissional dos dias de hoje. Segundo Sabino e Rocha (2004) “A valorização de habilidades diversas e perfeito domínio do idioma, da literatura e da história do seu país foram características exigidas a esses assessores de reis, imperadores, filósofos e líderes. Tais características incorporariam, mais tarde, o perfil do profissional de secretariado." (Sabino \& Rocha, 2004, p. 4)

Isso posto, o perfil do profissional de Secretariado desdobra-se em habilidades multidisciplinares, visto que durante sua formação levam-se em conta conteúdos que versam sobre questões administrativas, linguísticas, econômicas e legais. Portanto, devem possuir a) habilidades técnicas (tais como o uso de ferramentas tecnológicas); b) aptidão para redigir na sua língua nativa e em línguas estrangeiras; c) possuir habilidades conceituais para reconhecer a interdependência entre os assuntos e atividades da organização. Além delas, devem possuir habilidades humanas no intuito de assessorar seu administrador. Como evidenciam Sabino e Rocha, esse profissional deve ser "conhecedor de técnicas secretariais com excelência, comprometido com o trabalho, polivalente, negociador, programador de soluções, proativo e participativo". (Sabino \& Rocha, 2004, p. 95).

O secretário executivo é responsável por assessorar e dar suporte à equipe com quem trabalha, recepcionar pessoas, comunicar com diversos setores de uma organização, identificar necessidades de sua equipe, analisar a execução de tarefas, identificar objetivos e interesses dos fornecedores e consumidores em relação à organização, organizar roteiros de viagens e reuniões, realizar convocações verbal ou por escrito. Além disso, a ele cabe definir locais, datas e horários, fazer atas de reuniões, gerenciar documentos e arquivos da empresa em que trabalha, assim como organizar eventos para a instituição.

Segundo Carvalho (1998), o secretário executivo é um assessor executivo e administrador de informações que assessora a chefia/direção a processar e organizar informações. Precisa apresentar liderança, confiabilidade, espírito de equipe, criatividade, ética, discrição e dinamismo. Portanto, ele se encontra no nível estratégico da empresa, no qual a comunicação é um fator crucial para o desenvolvimento eficaz do trabalho, das tomadas de decisões, dos resultados do dia a dia e dos procedimentos necessários para o andamento das atividades do setor no qual ele está inserido. Segundo Carvalho e Grisson (2002), a comunicação tem efeito direto na qualidade do ambiente organizacional, e o 
secretário executivo, em razão de trabalhar com executivos de diferentes formações culturais e profissionais tem a tendência de assimilar diversas culturas e, com isso, a buscar o conhecimento dos novos processos comunicacionais, a fim de melhor atender as exigências do mercado.

Por ser um profissional que é capacitado para lidar com a gestão de informações e processos, possui habilidade com diferentes idiomas sabendo comunicar-se efetivamente neles. Por ter estado em contato com outros idiomas durante a sua formação, é pertinente que saiba lidar com a comunicação intercultural no ambiente empresarial. Ademais, por estarem inseridos em setores estratégicos há uma relação muito estreita entre o profissional de Secretariado Executivo e a Comunicação Intercultural, pois tais cenários demandam mais do que o conhecimento e a capacidade de se comunicar em outro idioma, mas também de como interpretar, mediar e abordar modelos culturais múltiplos.

\section{Metodologia}

Neste estudo utilizou-se a abordagem qualitativa, de cunho interpretativista e exploratório, buscando-se compreender e analisar situações e experiências cotidianas de secretários executivos no que concerne à comunicação em organizações multinacionais.

Segundo Diehl (2004), a pesquisa qualitativa descreve a complexidade de determinado problema, sendo necessário compreender e classificar os processos dinâmicos vividos nos grupos, contribuir no processo de mudança, e possibilitar o entendimento das mais variadas particularidades dos indivíduos. Além disso, faz-se valer esse método de pesquisa para o presente estudo, pois, segundo Cassell e Symon (1994), este possui como característica básica o foco na interpretação que os próprios participantes têm da situação sob estudo, enfatizando a subjetividade do participante em vez de sua objetividade.

Os dados que constituem o corpus de análise desta pesquisa foram gerados por meio de narrativas pessoais dos participantes, como forma de obter relatos de experiências e também para apresentar um parâmetro específico da representação dos contextos de trabalho em que profissionais egressos do curso em questão estão inseridos. Segundo Gibbs (2009), a narrativa é uma das formas fundamentais com que as pessoas organizam sua compreensão do mundo. Elas dão sentido a suas experiências passadas e possibilitam o compartilhamento dessas experiências com outros indivíduos. Além do mais, possibilitam através do fato 
narrado observar como as pessoas compreendem os eventos fundamentais em suas vidas e os contextos em que elas estão inseridas.

Para isso, um guia narrativo (anexo) foi planejado de forma que o participante refletisse de forma escrita sobre a sua formação e sua atual posição de trabalho. O guia apresentado aos participantes continha 11 perguntas direcionadas para que se orientassem durante o processo de escrita. Por meio dessas narrativas, foi possível traçar um ponto em comum levando-se em conta os desafios encontrados pelos participantes durante sua formação e, posteriormente, enquanto profissionais atuantes em organizações multinacionais.

As perguntas objetivaram conhecer o perfil do profissional de Secretariado Executivo e observar se durante sua formação inicial foram expostos a conteúdos e discussões específicas que enfatizassem questões relacionadas à comunicação intercultural relevantes para sua futura atuação. Além disso, buscou-se refletir sobre os desafios que este profissional enfrenta nas empresas. As perguntas também tinham o objetivo de obter informações sobre tópicos como as disciplinas lecionadas na graduação, o ensino e aprendizagem de idiomas, atividades extracurriculares realizadas durante o curso. Em um segundo momento, os encontros cotidianos em empresas multinacionais, os conhecimentos e habilidades específicas e indispensáveis requeridos na carreira. O guia narrativo, assim como um Termo de Consentimento Livre Esclarecido (anexo) com um resumo dos objetivos e esclarecimentos sobre a pesquisa, foram enviados por e-mail aos egressos do curso de bacharelado em Secretariado Executivo Trilíngue de uma universidade localizada no estado de Minas Gerais. Dos ex-alunos contatados, quatro dos que se dispuseram a participar preenchiam o perfil procurado (egressos e atuantes em empresas multinacionais). A maioria dos egressos para os quais foram enviados e-mails solicitando disponibilidade para participar da pesquisa não preenchia os requisitos da pesquisa por estarem trabalhando ora no setor público ora em empresas privadas nacionais. Ao final, somente três escreveram as narrativas e as submeteram dentro do prazo de três semanas previamente estabelecido. Para que a identidade dos participantes seja mantida, por questões éticas, serão utilizados pseudônimos (Baruch, Cirano e Elizabeth) escolhidos por eles próprios.

Todos os participantes desta pesquisa graduaram-se após a conclusão de todas as disciplinas comuns previstas por um mesmo currículo e conteúdo programático (catálogo de graduação do ano de 2008, versão simplificada pelos pesquisadores, anexa).

Para a análise dos dados os seguintes procedimentos foram realizados: a) redução dos dados por meio de ideias-chaves e conceitos (Creswell, 1998; Patton, 1990), que consiste na 
leitura dos documentos na busca por unidades heurísticas, que são as menores porções significativas interpretáveis que carregam em si significados abrangentes. Nessa fase, os dados são reduzidos por meio de frases curtas, palavras-chaves e conceitos, baseando-se atentamente às palavras e expressões utilizadas pelos participantes; b) codificação de dados em unidades significantes (Lincoln \& Guba, 1995), unidades estas que têm relativamente o mesmo conteúdo e, portanto, são colocadas dentro de categorias semelhantes; c) finalmente, o conjunto de categorias é revisado uma última vez, de forma a priorizar categorias de acordo com seu destaque, credibilidade, singularidade e conteúdo.

Com base na discussão teórica e na abordagem metodológica proposta nesta investigação, serão apresentadas a seguir as discussões e resultados que puderam ser evidenciados por meio da análise dos dados.

\section{Apresentação e Análise dos Resultados}

Pela análise interpretativa dos dados fornecidos pelos participantes, foi possível observar que o curso de Secretariado da instituição analisada ainda não abarca a questão da interculturalidade nas disciplinas lecionadas de forma sistematizada. O conhecimento adquirido sobre o assunto advém, na maioria das vezes, de estágios realizados pelos estudantes durante a graduação. Além disso, o ensino dos idiomas Inglês, Francês e Espanhol, apresenta níveis básico e intermediário, e são considerados pelos participantes como regular, pois não contêm conteúdo suficiente que os prepare para lidar com ambientes multiculturais.

De acordo com um dos participantes,

O curso XXX não é muito rigoroso no ensino de idiomas, portanto o aluno não precisa se dedicar muito para conseguir aprovação. [...] Poucos são os esforços para alinhar idioma e percepção cultural. O aluno pode aprender a língua, mas não há qualquer disciplina (obrigatória) sobre diferenças culturais. (Narrativa de Baruch)

Ademais, o participante comenta que

Durante a graduação não é exigido do aluno noção de ambientes multiculturais, mas como a maioria dos alunos tem grande interesse por línguas, eles acabam buscando este conhecimento paralelamente ao aprendizado oferecido. Alguns alunos conseguem adquirir experiência internacional através de intercâmbios durante a graduação e levam esta bagagem consigo para o mercado de trabalho. No meu caso, as duas experiências internacionais e minha relação com outras culturas me prepararam melhor para atuar em uma multinacional. (Narrativa de Baruch)

Baruch mostra que formar-se Secretario Executivo não é sinônimo de ser culturalmente sensível para entender realidades diversas ao que conhece. Muitas vezes, somente aqueles que se interessam por tal conteúdo o buscam por conta própria. Nesse 
sentido, consideram que a profissão requer aptidões que nem sempre são lecionadas na educação formal, como, por exemplo, aprender a ouvir, a lidar com pessoas, atender ao público e navegar bem por relações interpessoais, como evidencia Cirano no excerto a seguir:

Concluí as disciplinas sabendo que faltava um aprofundamento, porém as atividades extracurriculares me ajudaram muito a enfrentar o mercado de trabalho. Além de outros dois estágios, cito minha participação, durante quatro anos, na empresa júnior do curso, onde atuei nas áreas administrativas e em eventos. (Narrativa de Cirano)

Ainda sobre as aptidões lecionadas, outro participante cita que "as disciplinas foram satisfatórias, mas não são suficientes para preparar os estudantes para o mercado". Além disso, diz que se sentiu "preparada para o mercado de trabalho" pelo fato de ter combinado "a graduação com estágios.” (Narrativa de Elizabeth).

A respeito do conhecimento teórico ou prático sobre resolução de conflitos interculturais na empresa, foi relatado que não é oferecido ao longo do curso, e que os estudantes o obtém por meio de experiências extracurriculares. Um dos egressos relata, inclusive, que não se lembra de ter cursado disciplinas que ressaltassem o assunto de forma considerável, nem mesmo por meio de cursos ou disciplinas optativas. Relata, porém, que o conhecimento que obteve sobre o tema advém de uma disciplina cursada enquanto estava nos Estados Unidos, "Crisis Management, onde vi tipos de conflito e a forma de lidar com os mesmos, tanto no ambiente de trabalho quanto fora dele.” (Narrativa de Baruch)

O conhecimento acerca da resolução de conflitos é importante nos ambientes interculturais, pois auxiliam o Secretário Executivo em como lidar e enfrentar desafios diversos. Nas narrativas, pode-se observar que o contato com diferentes culturas e formas específicas de comportamento está muito presente no cotidiano das organizações multinacionais, e que cabe ao profissional de Secretariado Executivo atentar-se a essa diferença cultural. No cotidiano de trabalho de um dos participantes, foi mencionado que interações interculturais fazem parte de seu trabalho diário:

Tenho chefes e colegas de trabalho britânicos que tenho que lidar diariamente. As leis trabalhistas brasileiras são muito diferentes das leis do Reino Unido. Às vezes é difícil fazer com que eles entendam que uma determinada coisa é um direito, e não uma regalia. Eles acham estranho que os trabalhadores brasileiros queiram ter um bom plano de saúde, com preços justos, por exemplo. Perguntar sobre os benefícios oferecidos durante a entrevista de trabalho pode gerar desconforto. Ao entrar nesse trabalho, tive que passar por muitas inspeções de segurança, investigações e entrevistas sobre minha vida e da minha família, onde eles tocam em assuntos muito pessoais. É difícil ter que trabalhar sabendo que um colega de trabalho detém tantas informações sobre minha vida. Os britânicos consideram isso normal e conseguem ver o lado positivo e profissional disso tudo. Acredito que os brasileiros são mais objetivos e sucintos no ambiente empresarial. Tive que aprender que britânicos "'enfeitam" mais uma mensagem. Falar para alguém que um trabalho está ruim não é apropriado. Ao invés, preciso falar que determinada coisa poderia estar melhor, por exemplo. (Narrativa de Elizabeth)

R.G. Secr., GESEC, São Paulo, v. 9, n. 2, p 72-95, mai./ago. 2018. 
Elizabeth evidencia alguns pontos que se apresentam como relevantes. O primeiro relaciona-se ao entendimento das leis trabalhistas brasileiras por parte dos colegas e chefes britânicos e o modo como as entendem e não conseguem perceber que essas diferenças são culturais. Ao mesmo tempo, mostra que ao iniciar o trabalho neste contexto teve dificuldades em expor fatos pessoais de sua vida fora deste ambiente, algo que se torna culturalmente aceitável aos colegas britânicos. Outro ponto relevante diz respeito ao modo como teve de se adequar para evitar conflitos, visto que brasileiros parecem ser, na concepção da participante, mais diretos que os britânicos. Essas são diferenças culturais que, se não conhecidas por ela, poderiam gerar conflitos rotineiramente. Questões como essas deveriam ser exploradas durante a formação para que o profissional que tivesse um contato como o de Elisabeth fosse capaz de refletir para não cair na armadilha de interpretar certas questões como impróprias ou conflituosas. No cotidiano de outro participante, processos semelhantes também se fizeram presentes. Ele discorre sobre sua experiência profissional relatando que

Trabalho em uma multinacional americana, mas lido com profissionais do mundo todo com frequência. A empresa está em mais de 150 países, então temos que nos atentar às diferenças que possam existir. Os americanos, por exemplo, são pessoas que dizem por favor e obrigado sempre, então devemos cuidar para não deixarmos de corresponder. Às vezes só a inflexão de voz não é necessária para demonstrar cordialidade. Os latinos tendem a ser mais calorosos e informais, portanto devemos cuidar para que os assuntos não sejam tratados como em uma mesa de bar. (Narrativa de Baruch)

Segundo os entrevistados, a habilidade da comunicação intercultural vem do contato com o idioma, mas seria aprimorada com o ensino das diferenças culturais durante a graduação, de modo que fosse possível aproximá-los da compreensão de valores, comportamentos, crenças e costumes das culturas relacionadas aos idiomas estudados. Sobre tal aspecto foi pontuado por um dos participantes que

\begin{abstract}
o ensino de idiomas aplicado ao ambiente empresarial foi fraco, apesar das disciplinas específicas. O aprendizado de vocabulário de negócios contempla de forma limitada e principalmente arcaica o que eu encontrei em empresas multinacionais modernas. $\mathrm{O}$ estudo das diferenças culturais foi, na maioria das vezes, superficial. Esse tipo de conteúdo era apresentado na forma de "curiosidades" durante as aulas. O contato mais próximo que obtive das nuances culturais foi através de músicas e filmes locais, em oportunidades esporádicas. O meu contato mais profundo com a cultura de outro país foi quando cursei a disciplina optativa de Cultura Francesa. Nas aulas, a todo momento éramos confrontados com questões em voga nos países francófonos, inclusive assuntos bem atuais, desde conflitos políticos internos a preferências musicais dos jovens daquelas regiões. (Narrativa de Cirano)
\end{abstract}

Cirano demonstra ter estudado questões culturais relacionadas à cultura francesa, porém esse conhecimento foi abordado em uma disciplina não obrigatória. Se não fosse por interesse próprio em cursar a disciplina, passaria pelo curso sem essa formação específica. Tal excerto mostra a necessidade de que se ofereçam disciplinas mais direcionadas à discussão de 
cultura de forma mais aprofundada, a fim de promover reflexões sobre temas políticos, religiosos, dentre outros.

A partir do que foi exposto pelos participantes, o curso oferece disciplinas que expõem aos alunos os trâmites empresariais, mas que combinadas as atividades extracurriculares que a universidade disponibiliza, propicia uma melhor visão do mercado de trabalho. Esta questão pode ser observada no excerto de Elizabeth em que relata suas experiências extracurriculares:

Realizei dois estágios dentro do campus e trabalhei em alguns eventos pela Empresa Júnior. Os estágios foram essenciais para meu desenvolvimento e preparo. Eles me deixaram mais dinâmica e preparada para lidar com situações inesperadas e conflituosas. Acredito que eles me deram mais confiança para executar minhas atividades. Também fiz um intercâmbio estudantil nos Estados Unidos, onde pude escolher disciplinas variadas e que não eram oferecidas na XXX. Pude aprimorar alguns pontos em que não me sentia segura ainda, como apresentações em público, liderança, comunicação interpessoal e em grupos. (Narrativa de Elizabeth)

O tema precisa ser difundido com maior vigor ao longo do currículo do curso para preparar os alunos a lidarem com menos entraves e possam estar sempre prontos a saber decidir por qual caminho devem eleger para solucionar situações de conflito orientados pelas diferenças. Na narrativa, os egressos conceituaram a Comunicação Intercultural a partir de suas experiências pessoais com o curso e o mercado de trabalho. As respostas aproximaramse do conceito sugerido nesta pesquisa. Segundo um dos participantes, o conceito de Comunicação Intercultural "significa saber se relacionar com pessoas e culturas distintas das suas, sabendo como relevar o que pode ser conflitante para atingir um objetivo." (Narrativa de Baruch). Isso vai ao encontro do que Damen pondera sobre a Comunicação Intercultural. Segundo ele,

a interação de padrões culturais variados, crenças e valores que cada interlocutor traz ao processo de comunicação intercultural deve ser reconhecido em todo ato comunicativo; quanto maior a variação destes padrões, mais forte torna-se a força divisiva de tais variantes e maiores são as chances de falhas na comunicação (Damen, 1987, p. 24).

Assim, de acordo com um dos entrevistados

o curso de Secretariado e a universidade XXX preparam ( sic) profissionais curiosos, que procuram formas de complementar os conhecimentos transmitidos em sala de aula. Muitas vezes as aulas não são satisfatórias, mas a Universidade oferece outros caminhos para aprimorarmos nossas habilidades. Acredito que matérias que envolvam diferenças culturais seriam essenciais aos alunos, não somente para prepará-los para o ambiente de trabalho, mas também para o convívio em sociedade. (Narrativa de Elizabeth)

A partir da reflexão trazida pelos participantes, o curso oferece disciplinas que abrangem o mercado de trabalho, contribui com o ensino de três idiomas, e a universidade em si proporciona opções para o aluno se capacitar e se preparar para futuro profissional. Por outro lado, parece haver ainda uma carência de disciplinas que promovam reflexões mais

R.G. Secr., GESEC, São Paulo, v. 9, n. 2, p 72-95, mai./ago. 2018. 
diretamente sobre as diferenças culturais e o multiculturalismo que o profissional possivelmente encontrará na sua prática cotidiana. Além disso, a oferta de poucos semestres de ensino de línguas estrangeiras (quatro semestres de língua inglesa, quatro de língua francesa e três de língua espanhola), parece não ter sido suficiente para suprir as necessidades de formação profissional dos participantes desta pesquisa. Tal oferta reduzida de disciplinas foi uma adaptação curricular que entrou em vigor justamente no ano em que Baruch, Cirano e Elizabeth entraram no curso. Anteriormente, até o ano de 2007, o curso de graduação em Secretariado Executivo oferecia sete níveis (3,5 anos) de língua estrangeira e um nível de língua para fins empresariais, totalizando quatro anos de instrução em cada uma das duas línguas (inglês e francês). A partir de uma reformulação curricular, em 2008, em que a língua espanhola foi incorporada ao currículo básico do curso, a oferta das outras línguas sofreu, em contrapartida, uma redução de três semestres.

Com base no que foi exposto pelos participantes, tal redução da carga horária nas disciplinas de línguas não parece ter sido positiva, visto que se queixam do aprendizado de idiomas em nível intermediário. Além disso, com base nos dados gerados e analisados nesta pesquisa, é imperativa a reformulação curricular no sentido de incorporar disciplinas cujos conteúdos versam sobre as demandas atuais frente às novas questões que a globalização dos mercados tem instituído. Como sugestões de temas, propomos neste artigo disciplinas que focalizassem discussões específicas sobre a) cultura, diferenças e interculturalidade, b) inteligência e sensibilidade cultural, c) tomada de decisões e comunicação através das culturas, d) liderança através de culturas e e) gerenciamento de equipes multiculturais. Tais temas não necessariamente teriam de figurar disciplinas específicas, no entanto, deveriam fazer parte das discussões propostas pelas disciplinas de línguas estrangeiras. Entretanto, para tal inclusão de temas, ainda carentes para a Instituição de Ensino Superior em questão, seria necessária a ampliação da carga horária das disciplinas de línguas, quiçá como era antes da reformulação realizada quando os participantes desta pesquisa ingressaram no curso.

\section{Considerações Finais}

Por meio das narrativas analisadas nesta pesquisa foi possível observar que o estudo da Comunicação Intercultural se apresenta imperioso como forma de preparar o profissional de Secretariado Executivo a se adaptar às novas exigências e realidades do mercado corporativo. Entender o que o outro representa e ser sensível às diferenças auxilia esse 
profissional a desempenhar seu papel de assessorar setores da organização de forma mais efetiva.

Assim sendo, as empresas necessitam de profissionais que estejam cada vez mais cientes para lidar com encontros multiculturais, comunicando-se interculturalmente e garantindo que o desempenho no trabalho e nos trâmites próprios deste contexto sejam alcançados para, enfim, procurar evitar a ocorrência de situações inusitadas que podem causar conflitos.

Tendo em vista o perfil do profissional de Secretariado Executivo e observando que este deve ser capaz de se comunicar e transitar bem entre idiomas e culturas (visto que há chances de estarem em contato diário com um público advindo de diferentes experiências culturais) é necessário desenvolver, além das habilidades básicas reconhecidamente próprias da carreira, um perfil que considere uma formação que abarque conteúdos interculturais. Como é responsável pela comunicação e funciona como o elo entre diferentes setores de uma empresa, espera-se que possa realizar suas atribuições de forma exequível e fluida e, para tanto, o conhecimento intercultural apresenta-se como um dos novos desafios que o profissional se depara com frequência cada vez mais recorrente.

Retomando-se o objetivo principal desta pesquisa, foi possível refletir e concluir que frente a um mercado de trabalho cada vez mais globalmente integrado e, com efeito, mais exigente, o conhecimento estritamente técnico dos trâmites empresariais deve ser implementado com práticas, ainda no momento da formação inicial, que fomentem a sensibilidade e conhecimento de ambientes interculturais. Assim, faz-se necessário que tal conceito seja mais bem compreendido e explorado durante o processo de formação profissional para que venham a somar no sentido de progressivamente se instrumentalizem para os novos desafios impostos à carreira.

\section{Referências}

Carvalho, A. P. de \& Grisson, D. (2002). Manual do Secretariado Executivo (5a ed.). São Paulo: D'Livros.

Carvalho, A. P. de (1998). Manual do Secretário Executivo. São Paulo: D`Livros Editora. 
Cassell, C.; \& Symon, G. (1994). Qualitative methods in organizational research. London: Sage Publications.

Clanet, C. (1993). L'interculturel. Introduction aux approches interculturelles en education et en sciences humaines. Toulouse: Presses Universitaires du Mirail.

Craide, A.; \& Silva, F. B. (2012). A mobilidade e a gestão intercultural nas organizações. Rpca, Rio de Janeiro, vol. 6, n. 1, pp.105-123, jan./mar. Mensal.

Creswell, J. W. (1998). Qualitative inquiry and research design: Choosing among five traditions. Thousand Oaks, CA: Sage.

Damen, L. (1987). Culture learning: The fifth dimension in the language classroom. Reading (Massachusetts), Addison-Wesley Publishing Company.

Diehl, A. A. (2004). Pesquisa em ciências sociais aplicadas: métodos e técnicas. São Paulo: Prentice Hall.

Ferrari, M. A. (2015). Comunicação Intercultural: perspectivas, dilemas e desafios. In: Moura, C. P. de; \& Ferrari, M. A. Comunicação, interculturalidade e organizações: faces e dimensões da contemporaneidade. Rio Grande do Sul: Edipucrs.

Freitas, M. E. de. (2008). O imperativo intercultural na vida e na gestão contemporânea. Revista Organizações \& Sociedade. Salvador, vol. 15, n. 45, pp. 79-89, abr.-jun.

Gibbs, G. (2009). Análise dos dados qualitativos. Porto Alegre/RG: Editora Artmed, vol.1, pp.79-84.

Lincoln, Y. \& Guba, E. (1985). Naturalistic inquiry. Newbury Park, CA: Sage.

Martinelli, D. P.; Ventura, C. A. A.; \& Machado, J. R. (2004). Negociação internacional. São Paulo: Atlas. 
Nonato Júnior, R. (2009). Epistemologia e teoria do conhecimento em secretariado executivo: a fundação das Ciências da Assessoria. Fortaleza: Expressão Gráfica.

Patton, M. Q. (1990). Qualitative evaluation and research methods (2a ed.). Newbury Park, CA: Sage.

Ramos, N. (2009). Diversidade cultural, educação e comunicação intercultural - políticas e estratégias de promoção do diálogo intercultural. Revista Educação em Questão. (Vol. 34, n. 20, pp. 9-32). Natal.

Sabino, R. F.; \& Rocha, F. G. (2004). Secretariado: do escriba ao web writer (1a ed.). Rio de Janeiro: Brasport.

United Nation Education, Scientific and Cultural Organization (2001). Déclaration universelle sur la diversité culturelle. Paris: Unesco. 


\section{Anexos}

\section{Guia Narrativo}

Pesquisa: Comunicação intercultural em organizações multinacionais: os novos desafios do profissional de Secretariado Executivo

Esta pesquisa tem o objetivo de investigar como a formação na Universidade XXX colaborou para que os profissionais aqui graduados se tornassem competentes a lidar com encontros interculturais em sua atuação profissional cotidiana. Além disso, pretende compreender a relevância de se estudar questões relacionadas à comunicação intercultural presente nas organizações multinacionais ainda na universidade. Portanto, gostaríamos de contar com sua participação, enquanto ex-alunos do curso de Secretariado Executivo e atuantes em organizações multinacionais/internacionais para contar um pouco da sua experiência através de uma narrativa escrita (a partir do guia narrativo a seguir). Dessa forma, esperamos poder compreender com mais profundidade como o SEC colabora, em termos gerais, para a formação e sensibilidade intercultural dos seus alunos egressos, principalmente em relação a conhecimentos sobre resolução de conflitos em situações em que a comunicação intercultural está em jogo nas relações de trabalho na atualidade globalizada. Por fim, este trabalho pretende trazer reflexões, discussões e redirecionamentos para que novos conteúdos sobre as novas demandas do contexto empresarial global sejam implementados em cursos de Secretariado Executivo.

Questões éticas: em hipótese alguma sua identidade (sexo, idade ou empresa em que trabalha) será revelada ao longo do resultado da pesquisa. Para tanto, será utilizado um pseudônimo (escolhido por você) para identificá-lo. Se possível, insira um pequeno texto ao final da sua narrativa dizendo que está ciente sobre os objetivos do trabalho e as questões éticas que serão seguidas.

\section{Guia para a narrativa:}

As questões a seguir são apenas para direcioná-los durante a escrita das narrativas. Você deve respondê-las em forma de texto corrido, como se estivesse refletindo sobre a sua formação e sua atual posição onde trabalha. A pesquisa narrativa é uma ótima ferramenta 
para recortar uma dada realidade em que se objetiva trazer uma visão aprofundada de um dado fenômeno dentro da pesquisa qualitativa. Por favor, procure detalhar questões sobre a sua formação, conteúdos estudados para tentar fazer um paralelo da sua formação com a experiência que você tem com pessoas de outras línguas e culturas hoje. Quanto mais detalhes você puder fornecer, mais colaborará para uma visão mais profunda sobre o que venha a ser a comunicação intercultural e o papel do secretário executivo nestes contextos.

Desde já agradecemos por sua disponibilidade e ajuda.

\section{Guia narrativo}

1) Apresente-se (utilizando um pseudônimo que lhe agrade para ser utilizado durante a discussão das narrativas). Quando você iniciou sua graduação? Quando se graduou?

2) Como você caracteriza o ensino de línguas no curso de Secretariado Executivo Trilíngue da XXX? Explique.

3) Como você caracteriza o ensino sobre diferenças e sensibilidade cultural no curso de Secretariado Executivo Trilíngue da XXX? Comente.

4) Como você classificaria as disciplinas cursadas ao longo do curso? Ao terminar a graduação, como você se sentiu para enfrentar o mercado de trabalho? Comente, por favor.

5) Que tipo de atividades extracurriculares você realizou durante a sua formação acadêmica? Como você acredita que elas colaboraram para o trabalho que desempenha hoje? Comente.

6) Durante a graduação você obteve algum tipo de conhecimento teórico e ou prático sobre resolução de conflitos na empresa? Em quais disciplinas? Comente.

7) Qual a noção que você obteve na graduação sobre ambientes (empresas) multiculturais? Explique, por favor.

8) Quais conhecimentos você considera indispensáveis no cotidiano empresarial em que atua hoje? Quais você considera que não tinha plena competência ao finalizar seus estudos na universidade? Comente.

9) No seu cotidiano, como é o seu contato com pessoas de outras línguas e culturas? Você já presenciou situações em que a diferença cultural lhe causou algum tipo de estranhamento ou conflito (em reuniões, durante assessorias, em troca de correspondências ou e-mails, em telefonemas etc.) Você é capaz de lembrar alguns eventos? Como você se saiu? 
Paula, A. C. B., Sampaio, G. H. (2018)

Como o conhecimento teórico e prático adquirido na universidade contribuiu para que você lidasse com a situação?

10) O que significa comunicação intercultural para você? Você vê importância em saber sobre diferenças culturais no ambiente em que trabalha? Como a universidade contribuiu para esta visão?

11) Outros comentários que achar relevantes sobre o tema desta pesquisa.

Muito obrigado por sua participação.

Ao finalizarmos a pesquisa, enviaremos para vocês os resultados em forma de artigo para que possam expressar suas posições e reflexões acerca desta investigação. 
Catálogo de Graduação - Versão Simplificada pelos pesquisadores

\begin{tabular}{|l|l|l|l|}
\hline Exigência & Hora/aula & Prazos & Anos \\
\hline Disciplinas obrigatórias & 2.745 & Mínimo & 3,5 \\
\hline Disciplinas optativas & 240 & Padrão & 4 \\
\hline Estágio supervisionado & 480 & Máximo & 7 \\
\hline
\end{tabular}

\begin{tabular}{|l|}
\hline Sequência Sugerida \\
\hline $1^{\circ}$ Período \\
\hline ADM100 Teoria Geral da Administração \\
LET110 Língua Inglesa I \\
LET120 Língua Francesa I \\
SEC102 Leitura e Produção de Textos Empresariais \\
SEC130 Teoria Geral do Secretariado \\
\hline $2^{\circ}$ Período \\
\hline EDU110 Psicologia \\
INF103 Introdução à Informática \\
LET111 Língua Inglesa II \\
LET121 Língua Francesa II \\
SEC140 Técnicas e Tecnologia da Comunicação Oral \\
\hline $3^{\circ}$ Período \\
\hline DIR130 Instituições de Direito \\
ECO280 Sociologia \\
LET210 Língua Inglesa III \\
LET220 Língua Francesa III \\
SEC200 Redação Empresarial \\
\hline $4^{\circ}$ Período \\
\hline ECO270 Introdução à Economia \\
LET211 Língua Inglesa IV \\
LET221 Língua Francesa IV \\
SEC204 Redação Oficial 4 \\
SEC290 Metodologia de Pesquisa Aplicada ao Secretariado Executivo \\
\hline $5^{\circ}$ Período \\
\hline ADM110 Contabilidade Geral \\
LET170 Língua Espanhola I \\
SEC300 Arquivística \\
SEC310 Inglês Empresarial I \\
SEC320 Francês Empresarial \\
\hline $6^{\circ}$ Período \\
\hline ADM309 Organização, Sistemas e Métodos \\
LET171 Língua Espanhola II \\
SEC301 Gestão Documental 1 \\
SEC311 Inglês Empresarial II \\
EC400 Discurso Empresarial \\
\hline $7^{\circ}$ Período \\
\hline ERU365 Relações Internacionais \\
LET172 Língua Espanhola III \\
SEC330 Assessoria Executiva e Gestão Estratégica \\
\hline
\end{tabular}


Paula, A. C. B., Sampaio, G. H. (2018)

SEC412 Produção Escrita em Língua Inglesa

SEC499 Monografia

$8^{\circ}$ Período

SEC331 Assessoria Parlamentar e Gestão Pública

SEC419 Comunicação Oral em Língua Inglesa

SEC430 Gestão Secretarial e Empreendedora

SEC470 Espanhol Empresarial

SEC498 Estágio Supervisionado 
Termo de Consentimento Livre Esclarecido

Termo de Consentimento Livre Esclarecido: (deverá vir ao final da sua narrativa)

$\mathrm{Eu}$ estou ciente dos objetivos deste trabalho, das questões éticas nas quais se baseia e, portanto, concedo espontaneamente meus dados através de uma narrativa escrita em que conto minhas experiências de formação e atuação profissional. Estou ciente de que não serei exposto (nome, sexo, idade, ou empresa em que trabalho) em momento algum e minha identidade será expressa através de um pseudônimo, escolhido previamente por mim.

Data

Assinatura. 